\title{
Ethnocultural versus Basic Empathy: Same or Different?
}

\author{
Chato Rasoal $^{1}$, Tomas Jungert ${ }^{1,2}$, Stephan Hau ${ }^{3}$, Gerhard Andersson ${ }^{1}$ \\ ${ }^{1}$ Department of Behavioural Sciences and Learning, Linköping University, Linköping, Sweden; \\ ${ }^{2}$ Department of Psychology, McGill University, Montreal, Canada; \\ ${ }^{3}$ Department of Psychology, Stockholm University, Stockholm, Sweden. \\ Email: chato.rasoal@liu.se \\ Received September 27 $7^{\text {th }}, 2011$; revised October 28 $8^{\text {th }}, 2011$; accepted November $29^{\text {th }}, 2011$.
}

\begin{abstract}
The concept of ethnocultural empathy has been put forward as a variable that could explain tolerance between individuals and groups of different ethnic and cultural background. However, it is not clear if ethnocultural empathy is distinct from basic empathy. In this study we investigated the association between basic empathy, as measured by the Interpersonal Reactivity Index (Davis, 1983) and ethnocultural empathy, as measured by the Scale of Ethnocultural Empathy (Wang et al., 2003). We also explored the question of whether a set of background variables would predict the two forms of empathy. We investigated if there were different predictors of ethnocultural and basic empathy, and if the two constructs are distinct. Results showed that the two forms of empathy were correlated and that largely similar predictors were found for the two constructs. A confirmatory factor analysis failed to confirm two separate constructs. Implications of the findings for the measurement of empathy are discussed.
\end{abstract}

Keywords: Empathy, Ethnocultural Empathy, Culture, Contact Hypothesis

\section{Introduction}

Ethnocultural empathy is defined as empathy that is directed towards people from racial and ethnic cultural groups different from one's own ethnocultural group (Wang et al., 2003). The importance of an awareness of cultural factors for people who work with diverse populations is shown in several studies (Dyche \& Zayas, 2001; Kim, Kaplowitz, \& Johnston, 2004; Mercer \& Reynolds, 2002; Rasoal, Jungert, Hau, Edvardsson-Stiwne, \& Andersson, 2009; Ridley \& Lingle, 1996). Moreover, basic empathy, defined as the reactions of one individual to the observed experiences of another (Davis, 1983; Siu \& Shek, 2005), is held to be equally important in general interpersonal encounters and in professional settings (Alterman, McDermott, Cacciola, \& Rutherford, 2003; D’Ambrosio, Olivier, Didon, \& Besche, 2009; De Corte, Buysse, Verhofstadt, Roeyers, Ponnet, \& Davis, 2007; Duan \& Hill, 1996; Hojat, Mangione, Kane, \& Gonnella, 2005; Rasoal, Eklund, \& Hansen 2011).

In order to take cultural differences into consideration, there is a need to consider measures that test cultural empathy and test the ability to treat culturally-different individuals. One such measure is the Scale of Ethnocultural Empathy (SEE), which aims to measure "ethnocultural empathy" (Wang et al., 2003). This construct was developed from theories on general and cultural empathy by Wang et al. (2003) who claimed that it is a distinct concept from that of basic empathy. The validity of four subscales of the SEE; Empathic Feeling and Expression, Empathic Awareness, Acceptance of Cultural Differences and Empathic Perspective Taking was tested. Correlational analyses were used with four subscales from the Interpersonal Reactivity Index (IRI; Davis, 1983); Empathic Concern, Perspective Taking, Fantasy and Personal Distress. Significant correlations in the low-to-moderate range ( $r=.18$ to .54$)$ were found for each subscale of the IRI and each factor of the SEE including the total SEE score. The correlations between the SEE and IRI total scores were not reported. The study by Wang et al. (2003) was conducted in a college setting with undergraduate students.
Demographic characteristics were reported as homogenous, with few significant correlations. Wang et al. suggested that women were more ethnoculturally empathic than men and found that non-whites had higher scores than white participants on the SEE. In another study, gender differences on the SEE were also confirmed (Cunidiff \& Komarraju, 2008).

An important question, when considering ethnocultural empathy, is how distinct the concept is from a more basic empathy. Basic empathy is defined as a unipolar construct that has a multidimensional (affective and cognitive) component (Davis, 1983). Studies have found that basic empathy is predicted by age, gender (DiLalla, Hull, \& Dorsey, 2004; Eisenberg \& Lennon, 1983; Endresen \& Olweus, 2001; Pastor, 2004; Schieman \& Van Gundy, 2000) and finally, education (Alligood, 2007; Spencer, 2004), with higher education being associated with higher levels of empathy.

In the paper by Wang et al. (2003) SEE was moderately correlated with basic empathy, as measured by the two subscales on the IRI. They still concluded that the SEE measures a unique construct. In the present study we wanted to explore this association further. From a theoretical point of view, Pettigrew's (1998) contact hypothesis could be used to inform the search for predictors of ethnocultural empathy. This theory predicts that as a result of contact, negative attitudes held by an in-group member vis-à-vis an out-group member would, under certain conditions, alter so that it is less negative. In an interpersonal context, increased contact would promote and encourage friendships to develop between individuals belonging to different social groups. Consequently, members of different groups would increase their perceptions that they are more alike and reduce their perceptions of out-group homogeneity.

In this study, we had three aims.

First, we wanted to investigate the association between basic empathy, as measured by the IRI, and ethnocultural empathy, as measured by the SEE. We also included a measure of social desirability. We explored the idea that a set of background variables could predict the two forms of empathy. This is important as there is a possibility that there are different predictors 
of ethnocultural and basic empathy, and a question as to whether the two constructs are distinct. We decided to test for predictors of basic and ethnocultural empathy. Two predictors were derived from previous work on empathy because age and gender have been found to correlate with basic empathy (Davis, 1983). More specifically, females and older ages are associated with higher degrees of empathy. Two other predictors were added and were hypothesized to correlate with ethnocultural empathy. Initially, we tested conditions of upbringing, in terms of size of the city where the participant had been raised. This has been found to correlate with tolerance towards other minority ethnic groups, in line with the contact hypothesis (Enberg, Kälvemark, \& Ohlander, 1998; Pettigrew, 1998).

Second, we tested the importance of ethnic diversity in primary and secondary school. Again, according to the contact hypothesis, we assumed that more ethnic diversity in the school environment would be predictive of a higher level of reported ethnocultural empathy. We hypothesized that gender and age would be predictors of IRI and potentially of SEE because age and gender have been found to correlate with basic empathy. Finally, in line with the contact hypothesis, we predicted that only ethnocultural empathy would be predicted by ethnic diversity in the school.

Third, we conducted a confirmatory factor analysis in which the subscales of the SEE and IRI were entered to test if the two constructs of ethnocultural empathy and basic empathy were distinct. Our prediction was that they would be separated.

\section{Method}

\section{Participants and Procedure}

There were 788 participants from undergraduate and secondary schools in Sweden. Ages ranged from 15 to 48 years $(M=$ $24.3, S D=5.9)$. Participants completed questionnaires in large groups in class. In the questionnaires we asked the participants about their gender, age, ethnicity, size of the city where they grew up, the degree of ethnic diversity in their primary and secondary schools and their native language. The response rate was $66 \%$. In all, 553 participants were female $(70 \%)$ and 235 were male $(30 \%)$. Most of the respondents described themselves as ethnic Swedes (see Table 1 for further descriptions). The anonymity and confidentiality of the respondents were guaranteed and participation was on a voluntary basis. They could withdraw from the study at will. It took participants approximately 20 minutes to complete a questionnaire.

\section{Measures}

The questionnaire was made up of a booklet, which consisted of 85 items in total, and consisted of four parts:

1) Questionnaire on demographics.

2) The Scale of Ethnocultural Empathy (Rasoal, Jungert, Hau, \& Andersson, 2011; Wang et al., 2003), which is intended to measure intellectual and emotional expressions of empathy, aimed at people and groups who have an ethnic background different from one's own. The SEE is a 31-item, forced-choice self-report measure that produces an overall score and four subscale scores (see Appendix); Factor 1: Empathic Feeling and Expression (EFE); Factor 2: Ethnocultural Empathy Awareness (EA); Factor 3: Acceptance of Cultural Differences (AC); and Factor 4: Empathy Perspective Taking (EP) (Wang et al., 2003). In this study we focus on the SEE-total score. Wang et al. (2003) reported an internal consistency of $\alpha=.91$. In the sample, the internal consistency was $\alpha=.87$. Scores for the SEE are obtained by adding item scores. Higher scores indicated a higher
Table 1.

Demographic characteristics of the sample $(N=788)$.

\begin{tabular}{|c|c|c|}
\hline & Variable & Frequency in $\%(\mathrm{~N})$ \\
\hline \multirow{2}{*}{ Gender } & Male & $29.8(235)$ \\
\hline & Female & $70.2(553)$ \\
\hline \multirow{9}{*}{ Ethnicity } & Swedish & 92.8 \\
\hline & Bosnian & 1.4 \\
\hline & Finish & 1.1 \\
\hline & Latin American & 0.8 \\
\hline & Iranian & 0.5 \\
\hline & Polish & 0.5 \\
\hline & Croatian & 0.5 \\
\hline & Other & 2.4 \\
\hline & Age $15-19$ & 13.0 \\
\hline \multirow{4}{*}{ Age } & Age $20-23$ & 45.7 \\
\hline & Age $24-28$ & 25.5 \\
\hline & Age $29-33$ & 6.5 \\
\hline & Age $34-48$ & 9.3 \\
\hline \multirow{3}{*}{ Place of growth } & City (e.g., Stockholm) & 33.0 \\
\hline & $\begin{array}{c}\text { Town } \\
\text { (50000 inhabitants or more) }\end{array}$ & 18.8 \\
\hline & $\begin{array}{c}\text { Village } \\
\text { (less than } 50000 \text { inhabitants) }\end{array}$ & 48.1 \\
\hline \multirow{3}{*}{ Primary school } & With most Swedes & 74 \\
\hline & Mixed ethnicity & 21.7 \\
\hline & With most non-Swedes & 4.2 \\
\hline \multirow{3}{*}{ Secondary school } & With most Swedes & 60.4 \\
\hline & Mixed ethnicity & 37.1 \\
\hline & With most non-Swedes & 2.5 \\
\hline
\end{tabular}

level of ethnocultural empathy. The Swedish translation of the SEE has been previously validated on an independent sample (Rasoal et al., 2011).

3) Respondents also completed the Interpersonal Reactivity Index (IRI: Davis, 1996), which includes 28 items and is designed to tap four separate dimensions of basic empathy. We used the total score of the IRI in the analyses, but in a confirmatory factor analysis, we used the subscales (see Appendix). Factor 1: Fantasy (FS); Factor 2: Perspective Taking (PT); Factor 3: Empathetic Concern (EC); and Factor 4: Personal Distress (PD). Both the internal (alpha coefficients for total IRI, which ranged from $\alpha=.70$ to .78 for the subscales) and the test-retest reliabilities (from .61 to .81 over a period of two months) could be regarded as acceptable (Davis, 1983). In the present study the alpha was $\alpha=.73$.

4) Finally, we administered the Impression Management Subscale (IMS: Paulhus, 1988). The IMS has 20 items and is designed to measure the desire to create a favourable impression on others. This last scale was included because we suspected that some students might be worried that their responses could be associated with racism and discrimination (Paulhus, 1988). All of the items were rated on a five-point Likert-type scale $(1=$ strongly disagree to $5=$ strongly agree). The items were phrased both positively and negatively to balance any potential response bias. Negatively-phrased items were re- 
versed in the scoring. Paulhus (1988) reported a coefficient alpha of .79 for total IMS. In this study the alpha was .70 .

\section{Data Analysis}

Multiple regression analysis was conducted using SPSS 16.0 in order to find out which (predictor) dependent variable best predicts basic empathy and ethnocultural empathy. For the confirmatory factor analysis we used EQS 6.1 to test the higher order factor structure of the SEE and the IRI using the subscales of the measures.

\section{Results}

In Table 2, we present descriptive statistics and intercorrelations between the empathy scales and the impression management scale.

Next, we computed two, multiple linear regressions. In the first one we used the total score on the ethnocultural empathy (SEE) and in the second one we used the total score of the basic empathy (IRI) as (criterion) dependent variables. Five (predictors) independent variable were entered into the linear regression using the "enter" method (see Table 1 for a description). The model, with SEE as a dependent variable, showed that gender, place of growth and age were significantly related to higher ethnocultural empathy (see Table 3).

We also tested the same set of variables as predictors of basic empathy (IRI). This second, multiple regression equation was also important, with a significant contribution of gender, place of upbringing and age (Table 4).

\section{Confirmatory Factor Analysis (CFA)}

A CFA was used to test if a higher order, two-factor structure would be obtained. The first factor specified the four subscales of the SEE (Wang et al., 2003). The second factor included the four subscales of the IRI (Davis, 1983). We used EQS 6.1 (Bentler, 2006) to specify the expected factor loadings. We used the fit indices that $\mathrm{Hu}$ and Bentler (1999) recommend in order to evaluate model fit for this study. These fit indices include the standardized root mean square residual (SRMR), the comparative fit index (CFI), the root mean square error of approximation (RMSEA), and the Satorra-Bentler $\chi^{2}$. Results showed that the fit of the proposed two-factor model was poor $\left(\right.$ Satorra-Bentler $\chi^{2} / \mathrm{df}=46.7, \mathrm{CFI}=.60, \mathrm{RMSEA}=.24,90 \%=$ $(0.23 ; 0.25), \mathrm{SRMR}=.26)$.

\section{Discussion}

In this study we investigated the association between basic empathy as measured by the IRI and ethnocultural empathy as measured by the SEE. Second, we explored whether a set of background variables could predict the two forms of empathy. We found a significant, strong correlation between basic and ethnocultural empathy, suggesting that the two factors overlap substantially. We failed to find any differential predictors, again suggesting that the two forms of empathy are similar. Finally, we used CFA to test the higher order factor structure and found that the two measures were not distinct.

Turning to our first question, our data do not concord with Wang et al. (2003) who regarded ethnocultural empathy as a unique construct. On the contrary, it could be that an underlying empathy factor influences the ratings on both the SEE and the IRI. This did not alter the conclusion that the two constructs
Table 2.

Descriptive statistics and inter-correlations between ethnocultural empathy (SEE), basic empathy (IRI), and impression management scale (IMS) $(N=788)$.

\begin{tabular}{cccccc}
\hline & $M$ & $(S D)$ & SEE & IRI & IMS \\
\hline SEE & 3.48 & 0.52 & - & $.65^{* *}$ & $.20^{* *}$ \\
IRI & 3.32 & 0.38 & & & $.21^{* *}$ \\
IMS & 2.87 & 0.49 & & & \\
\hline
\end{tabular}

$* * P<.001$.

Table 3.

Multiple regression analysis predicting ethnocultural empathy from background variables $(N=788)$.

\begin{tabular}{cccccc}
\hline Independent variable & $R$ square & Adj. $R$ square & $\beta$ & $t$ & $p$ \\
\hline Gender & & & -.19 & -5.60 & $.00^{* *}$ \\
Place of growth & & .13 & 3.66 & $.00^{* *}$ \\
Primary school & .08 & 0.08 & .07 & 1.71 & .08 \\
Secondary school & & & .06 & 1.43 & .15 \\
Age & & .16 & 4.43 & $.00^{* *}$ \\
\hline
\end{tabular}

$F(5.777)=13.68 ; * * P<.001$.

Table 4.

Multiple regression analysis predicting basic empathy from background variables $(N=788)$.

\begin{tabular}{cccccc}
\hline Independent variable & $R$ square & Adj. $R$ square & $\beta$ & $t$ & $p$ \\
\hline Gender & & -.28 & -8.34 & $.001^{* *}$ \\
Place of growth & & .14 & 4.14 & $.001^{* *}$ \\
Primary school & .11 & 0.10 & .06 & 1.61 & .11 \\
Secondary school & & & .02 & 0.62 & .53 \\
Age & & .08 & 2.18 & $.03 *$ \\
\hline
\end{tabular}

$F(5.777)=18.71 ; * * P<.001 ; * P<.05$.

overlap. As social desirability might affect the ratings, both empathy scales were correlated with the measure of impression management. The findings suggest that a significant proportion of variance on the empathy scales can be explained by scores on the IMS. Wang et al. (2003) found a correlation of $r=.23$ between the SEE and the measure of impression management in their validation study. However, the main purpose of this study was to test if basic and ethnocultural empathy are distinct. Controlling for scores on the IMS did not alter the correlation between the SEE and the IRI $(r=.64)$ and hence we do not believe that social desirability lies behind the association.

Our second aim was to investigate differential correlates of the two forms of empathy. The multiple regression analysis revealed that gender, place where one grows up and age were predictive of both ethnocultural empathy and basic empathy. This again questions the unique status of ethnocultural empathy. Participants, who grew up in a small city, were women, were older, and had higher levels of ethnocultural empathy. However, contrary to our expectation, the ethnic diversity in the primary and secondary schools of the students was not a significant predictor variable of ethnocultural empathy. Overall, our predictions were not confirmed and no clear differential predictors were found.

Our third aim was to test if ethnocultural empathy and basic empathy are distinct when defined by their subscales. Results of 
the CFA showed that a two-factor model had an inadequate fit with the data. There are two possible reasons why a two-factor model did not fit the data. First, the two measures do not seem to tap two distinct constructs, which is contrary to what Wang et al. (2003) claimed. Second, our data set included a rather homogenous sample, with only students from one university and secondary schools. However, the CFA, together with the high correlation between the two scales and the results of the regression analyses, support the notion that the two scales measure basically the same variable or share variance with a third, common empathy construct. Overall, this was not in line with our hypotheses. To conclude, basic empathy and ethnocultural empathy are highly interdependent. However, more research is needed in this area before we will know how stable the relationship between the two constructs is. Thus, at this point, we do not claim that it is possible to translate basic empathy to community empathy at a collective level.

This study raises questions regarding how ethnocultural empathy should be measured. In particular, in light of the significant association between impression management and empathy, it might be that more indirect and implicit measures of empathy should be used (e.g., Batson, Polycarpou, Harmon-Jones, Imhoff, \& Mitchener, 1997). On the other hand, more experimental set-ups are hardly possible to administer in large samples and therefore we believe that our self-reported findings add to the literature on ethnocultural empathy. From a theoretical point of view, we found no support for the contact hypothesis that experience of ethnic diversity in a school does not predict empathy ratings.

\section{Limitations of the Study}

There are two main limitations of this study. First we had a relatively homogenous sample in a university and a secondary school setting, with most participants being ethnic Swedes. Future research could incorporate a wider range of participants with respect to ethnicity and education. Second, we relied on self-reporting measures that were translated from English into Swedish. It could be that measures of empathy and, in particular ethnocultural empathy, do not translate easily to other settings. On the other hand, our measures were generally well understood and, as Sweden is a multicultural society with a significant minority of immigrants $(20 \%)$, it made sense to measure ethnocultural empathy.

\section{References}

Alligood, M. R. (2007). Rethinking empathy in nursing education: Shifting to a developmental view. In S. Leibold, \& F. Maureen, (Eds.), Middle range theory development using King's conceptual system (pp.287-296). New York, NY: Springer Publishing Co.

Alterman, A. I., McDermott, P. A., Cacciola, J. S., \& Rutherford M. J. (2003). Latent structure of the Davis interpersonal reactivity index in methadone maintenance patients. Journal of Psychopathology and Behavioral Assessment, 25, 257-265. doi:10.1023/A:1025936213110

Batson, C. D., Polycarpou, M. P., Harmon-Jones, E., Imhoff, H. J., \& Mitchener, E. C. (1997). Empathy and attitudes: Can feeling for a member of a stigmatized group improve feelings toward the group? Journal of Personality and Social psychology, 72, 105-118. doi:10.1037/0022-3514.72.1.105

Bentler, P. M. (2006). EQS 6 structural equations program manual. Encino: Multivariate Software, Inc.

Cunidiff, L. N., \& Komarraju, M. (2008). Gender differences in ethnocultural empathy and attitudes toward men and women in authority. Journal of Leadership \& Organizational Studies, 15, 5-15. doi: $10.1177 / 1548051808318000$

D’Ambrosio, F., Olivier, M., Didon, D., \& Besche, C. (2009). The basic empathy scale: A French validation of a measure of empathy in youth. Personality and Individual Differences, 46, 160-165. doi:10.1016/j.paid.2008.09.020

Davis, M. H. (1983). Measuring individual differences in empathy: Evidence for a multidimensional approach. Journal of Personality and Social Psychology, 44, 113-126.

doi:10.1037/0022-3514.44.1.113

Davis, M. H. (1996). Empathy: A social psychological approach. Madison, WI: Brown \& Benchmark.

De Corte, K., Buysse, A., Verhofstadt, L. L., Roeyers, H., Ponnet, K., \& Davis, M. H. (2007). Measuring empathic tendencies: Reliability and validity of the Dutch version of the interpersonal reactivity index. Psychologica Belgica, 47, 235-260.

DiLalla, L. F., Hull, S. K., \& Dorsey, J. K. (2004). Effect of gender, age, and relevant course work on attitudes toward empathy, patient spirituality, and physician wellness. Teaching and Learning in Medicine, 16, 165-170. doi:10.1207/s15328015tlm1602 8

Duan, C., \& Hill, C. (1996). The current state of empathy research. Journal of Counselling Psychology, 3, 261-274. doi:10.1037/0022-0167.43.3.261

Dyche, L., \& Zayas, L. H. (2001). Cross-cultural empathy and training the contemporary psychotherapist. Clinical Social Work Journal, 29, 245-258. doi:10.1023/A:1010407728614

Eisenberg, N., \& Lennon, R. (1983). Sex differences in empathy and related capacities. Psychological Bulletin, 94, 100-131. doi:10.1037/0033-2909.94.1.100

Enberg, J., Kälvemark, S., \& Ohlander, A.-S. (1998). The best generation. Falun: AiT Scandbook.

Endresen, I. M., \& Olweus, D. (2001) Self-reported empathy in Norwegian adolescents: Sex differences, age trends, and relationship to bullying. In A. C. Bohart, \& D. J. Stipek (Eds.), Constructive \& destructive behavior: Implications for family, school, \& society (pp. 147-165). Washington, DC: American Psychological Association.

Hojat, M., Mangione, S., Kane, G. C., \& Gonnella, J. S. (2005). Relationships between scores of the Jefferson scale of physician empathy (JSPE) and the interpersonal reactivity index (IRI). Medical Teacher, 27, 625-628. doi:10.1080/01421590500069744

Hu, L., \& Bentler, P. M. (1999). Cutoff criteria for fit indexes in covariance structure analysis: Conventional criteria versus new alternatives. Structural Equation Modeling, 6, 1, 55.

Kim, S. S., Kaplowitz, S., \& Johnston, M.V. (2004). The effects of physician empathy on patient satisfaction and compliance. Journal of Evaluation and the Health Professions, 27, 237-251. doi: $10.1177 / 0163278704267037$

Mercer, S.W., \& Reynolds, W. J. (2002). Empathy and quality of care. The British Journal of General Practice, 52, 9-12.

Pastor, A. R. (2004). Differences in empathy in gender and age. Apuntes de Psicologia, 22, 323-339.

Paulhus, D. L. (1988). Assessing self-deception and impression management in self-report: The balanced inventory of desirable responding. Vancouver: Department of Psychology, University of British Colombia

Pettigrew, T. F. (1998). Intergroup contact theory. Annual Review of Psychology, 49, 65-85. doi:10.1146/annurev.psych.49.1.65

Rasoal, C., Jungert, T., Hau, S., \& Andersson, A. (Accepted). Development of a Swedish version of the Scale of Ethnocultural Empathy. Psychology, 2, 568-573.

Rasoal, C., Eklund, J., \& Hansen, E. (2011). Toward conceptualization of ethnocultural empathy. Journal of Social, Evolutionary, and Cultural Psychology, 5, 1-13.

Rasoal, C., Jungert, T., Hau, S., Edvardsson-Stiwne, E., \& Andersson, A. (2009). Ethnocultural and basic empathy among students in health education. Evaluation \& the Health Profession, 3, 300-313. doi: $10.1177 / 0163278709338569$

Ridley, C. R., \& Lingle, D. W. (1996). Cultural empathy in multicultural counselling: A multidimensional process model. In P. B. Pedersen, \& J. G. Draguns (Eds.), Counselling across culture $\left(4^{\text {th }} \mathrm{ed}\right.$., pp. 21-46). Thousand Oaks, CA: Sage.

Schieman, S., \& Van Gundy, K. V. (2000). The personal and social links between age and self-reported empathy. Social Psychology Quarterly, 63, 152-174. doi:10.2307/2695889 
Siu, M. H. A., \& Shek, T. L. D. (2005). Validation of the interpersonal reactivity index in a Chinese context. Research on Social Work Practice, 15, 118-126. doi:10.1177/1049731504270384

Spencer, J. (2004). Decline in empathy in medical education: How can we stop the rot? Medical Education, 38, 916-918. doi:10.1111/j.1365-2929.2004.01965.x
Wang, Y.-W., Bleier, J., Davidson, M., Savoy, H., Tan, J., \& Yakushko, O. (2003). The scale of ethnocultural empathy. Development, validation, and reliability. Journal of Counselling Psychology, 2, 221-234. doi:10.1037/0022-0167.50.2.221 


\section{Appendix}

\section{Scale of Ethnocultural Empathy (SEE, Adapted from the Original Scale, See Wang et al., 2003)}

1) I feel annoyed when people do not speak standard Swedish.

2) I don't know a lot of information about important social and political events of ethnic groups other than my own.

3) I am touched by movies or books about discrimination issues faced by racial or ethnic groups other than my own.

4) I know what it feels like to be the only person of a certain ethnicity in a group of people.

5) I get impatient when communicating with people from other ethnic backgrounds, regardless of how well they speak Swedish.

6) I can relate to the frustration that some people feel about having fewer opportunities due to their ethnic backgrounds.

7) I am aware of institutional barriers (e.g., restricted opportunities for job promotion) that discriminate against racial or ethnic groups other than my own.

8) I don't understand why people of different ethnic back0 grounds enjoy wearing traditional clothing.

9) I seek opportunities to speak with individuals of other ethnic backgrounds about their experiences.

10) I feel irritated when people of different ethnic background speak their language around me.

11) When I know my friends are treated unfairly because of their ethnic backgrounds, I speak up for them.

12) I share the anger of those who face injustice because of their ethnic backgrounds.

13) When I interact with people from other ethnic backgrounds, I show my appreciation of their cultural norms.

14) I feel supportive of people of other ethnic groups, if I think they are being taken advantage of.

15) I get disturbed when other people experience misfortunes due to their ethnic background.

16) I rarely think about the impact of a racist or ethnic joke on the feelings of people who are targeted.

17) I am not likely to participate in events that promote equal rights for people of all ethnic backgrounds.

18) I express my concern about discrimination to people from other ethnic groups.

19) It is easy for me to understand what it would feel like to be a person of another ethnic background other than my own.

20) I can see how other ethnic groups are systematically oppressed in our society.

21) I don't care if people make racists statements against other ethnic groups.

22) When I see people who come from a different ethnic background succeed in the public arena, I share their pride.

23) When other people struggle with ethnic oppression, I share their frustration.

24) I recognize that the media often portrays people based on ethnic stereotypes.

25) I am aware of how society differentially treats ethnic groups other than my own.

26) I share the anger of people who are victims of hate crimes (e.g., intentional violence because of ethnicity).

27) I do not understand why people want to keep their indigenous ethnic cultural traditions instead of trying to fit into the mainstream.

28) It is difficult for me to put myself in the shoes of someone who is ethnically different from me.
29) I feel uncomfortable when I am around a significant number of people who are ethnically different than me.

30) When I hear people make racist jokes, I tell them I am offended even though they are not referring to my ethnic group.

31) It is difficult for me to relate to stories in which people talk about ethnic discrimination they experience in their day to day lives.

\section{Interpersonal Reactivity Index (IRI; Davis, 1983)}

1) I daydream and fantasize, with some regularity, about things that might happen to me (FS).

2) I often have tender, concerned feelings for people less fortunate than me (EC).

3) I sometimes find it difficult to see things from the "other guy's" point of view (PT) (-).

4) Sometimes I don't feel very sorry for other people when they are having problems (EC) (-).

5 ) I really get involved with the feelings of the characters in a novel (FS).

6) In emergency situations, I feel apprehensive and ill-atease (PD).

7) I am usually objective when I watch a movie or play, and I don't often get completely caught up in it (FS) (-).

8) I try to look at everybody's side of a disagreement before I make a decision (PT)

9) When I see someone being taken advantage of, I feel kind of protective towards them (EC).

10) I sometimes feel helpless when I am in the middle of a very emotional situation (PD).

11) I sometimes try to understand my friends better by imagining how things look from their perspective (PT).

12) Becoming extremely involved in a good book or movie is somewhat rare for me (FS) (-).

13) When I see someone get hurt, I tend to remain calm (PD) $(-)$.

14) Other people's misfortunes do not usually disturb me a great deal (EC) (-).

15) If I'm sure I'm right about something, I don't waste much time listening to other people's arguments (PT) (-).

16) After seeing a play or movie, I have felt as though I were one of the characters. (FS)

17) Being in a tense emotional situation scares me (PD).

18) When I see someone being treated unfairly, I sometimes don't feel very much pity for them (EC) (-).

19) I am usually pretty effective in dealing with emergencies (PD) (-).

20) I am often quite touched by things that I see happen (EC).

21) I believe that there are two sides to every question and try to look at them both (PT).

22) I would describe myself as a pretty soft-hearted person (EC)

23) When I watch a good movie, I can very easily put myself in the place of a leading character (FS).

24) I tend to lose control during emergencies (PD).

25) When I'm upset at someone, I usually try to "put myself in his shoes" for a while (PT)

26) When I am reading an interesting story or novel, I imagine how I would feel if the events in the story were happening to me (FS).

27) When I see someone who badly needs help in an emergency, I go to pieces (PD).

28) Before criticizing somebody, I try to imagine how I would feel if I were in their place (PT). 